EGTRIB Journal

JOURNAL OF

THE EGYPTIAN SOCIETY OF TRIBOLOGY

VOLUME 18, No. 4, October 2021, pp. 37 - 44 ISSN 2090 - 5882

(Received September 13. 2021, Accepted in final form September 25. 2021)

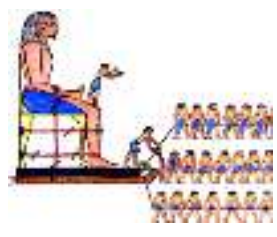

jest.journals.ekb.eg

\title{
TRIBOLOGICAL BEHAVIOR ASSESSMENT OF 3D PRINTED PLA+ SAMPLES IMPREGNATED WITH LIQUID ANAEROBIC METHACRYLATE LUBRICANT
}

\author{
Mostafa A., Khalifa A., Mahmoud M. and Marzouk W. W. \\ Production Engineering and Mechanical Design Department, Faculty of Engineering, Minia University, \\ Egypt.
}

\begin{abstract}
Nowadays, the world of production and manufacturing engineering has been witnessed a remarkable development in manufacturing techniques. 3D printing additive manufacturing method is the last witness of that progress. As a result of appearing additive manufacturing technique, it had to be studied it on the tribology field, which plays a crucial role in most of the engineering applications and our life. Therefore, the effect of infill pattern (Grid, Triangles, and Concentric) and infill density $(20 \%, 60 \%$, and $100 \%$ ) parameters have been studied in this paper in each dry and lubricant modes. The experimental results presented that the highest and lowest values of friction coefficient were occurred in cases of the Grid sample with $100 \%$ infill density and without lubrication, and the Triangles sample with $20 \%$ infill density and with lubrication, respectively. The lower friction coefficient is linked with the lower infill density $(20 \%)$ because of the lower contact surfaces. This could be attributed to the lower contact surfaces which are subjected to friction. And the highest and the lowest values of wear rates were took placed in the cases of Grid sample with $\mathbf{2 0 \%}$ infill density and without lubrication, and Grid sample with $20 \%$ infill density and with lubrication, respectively. The wear rate behavior is attributed to the protective film of lubrication which prevents the surface damage and wear.
\end{abstract}

\section{INTRODUCTION}

The economics in the industrial sectors have attained much attention and became a global attitude in recent days. Rapid prototyping offers many economic benefits over the traditional manufacturing techniques in which it cuts the costs of skilled workers, decreases the manufacturing time, is suitable for complex products, etc., [1]. 3D printing is considered one of the most common methods of additive manufacturing which affords good economics of production along with reasonable accuracy, [2]. Due to the numerous advantages of $3 \mathrm{~d}$ printing additive manufacturing, the applications of this technique extend to aerospace, automotive, medical, civil aviation applications, [3]. 3D printing employs thermoplastic heat-formable materials (PLA, ABS, etc.), [4]. However, the 3d printing additive manufacturing could overcome many problems where the recent manufacturing techniques suffer from, the mechanical and operating performance of the printed products is still a concern, and the question of whether the printed product can compete with the products which are fabricated by the traditional methods is still open. Therefore, many researchers investigated the mechanical properties of the printed parts 
[5, 6]. Kumar et al, [7] evaluated the mechanical performance of 3-D printed tensile specimen with fused deposition modeling by using multi blended [01 layer PLA + 01 layer of PLA + polyvinyl chloride + 02 layers of PLA + wood powder + 02 layers of PLA + $\mathrm{Fe}_{3} \mathrm{O}_{4}$, each with layer thickness of $0.53 \mathrm{~mm}$ ]. and hybrid blended [PLA 50 wt.\%, PVC 25 wt.\%, magnetite powder $20 \mathrm{wt} . \%$, and wood powder $5 \mathrm{wt} . \%$ ] polylactic acid (PLA) matrix. They found that the multi blended PLA outperformed the hybrid blended PLA under the same testing conditions. Furthermore, the printed PLA can be reinforced by short carbon fibers to achieve more enhanced mechanical behavior, [8]. Interestingly, Sing et al reported that the PLA+ recorded higher tensile strength in the comparison with the common PLA, [9]. Moreover, PLA+ showed resistance effect against SARS-CoV-2 (COVID-19), thus frames for face shields and protective googles are potential applications for PLA+, [10]. The infill pattern plays a vital role in the mechanical properties of the printed PLA+. Harpreet et al proved that the grid pattern exhibited the best bearing and mechanical performances among different kinds of infill patterns, [11]. To the author's knowledge, very few studies have been accomplished to evaluate the tribological properties of printed PLA and PLA+, however, the sliding components like bearing races, gears, etc are potential applications. Robert et al, [12] revealed that the printed PLA with $10 \mathrm{wt} . \%$ of graphite showed the lowest wear rate. Nevertheless, the graphite had an adverse influence on the fracture stress and lower strength.

The present study investigates the effect of infill pattern and density on the tribological behavior of PLA+ printed samples. Furthermore, an innovative approach is used to fabricate a liquid lubricant impregnated in printed PLA+ specimens at different infill patterns and densities.

\section{EXPERIMENTAL}

Polylactic Acid Plus (PLA+) filament with $1.75 \mathrm{~mm}$ diameter has been used in this study as a building material of tensile specimens because this material is the most popular and used one in 3d printing additive of polymeric materials. PLA+ was purchased from Shenzhen Esun Industrial Co., Ltd. The chemical composition of the used material (Provided by the supplier) is shown in Table 1. The mechanical and physical properties of the used material (Provided by the supplier) are shown in Table 2. Anaerobic methacrylate in the liquid phase was pressed through the PLA+ samples passages to ensure that the liquid fills the voids in the printed samples. Anaerobic methacrylate was selected as a filler material because of its lubrication properties. Anaerobic methacrylate was supplied by LOXEAL company. Regarding the counterface, stainless steel (Grade 316) disc was used as a counterface with a thickness of $1 \mathrm{~mm}$.

Table 1 The chemical composition of PLA+

\begin{tabular}{|c|c|}
\hline Ingredient Name & Content $(\%)$ \\
\hline Polylactide resin & 98 \\
\hline Calcium carbonate & 2 \\
\hline
\end{tabular}

Table 2 The mechanical and physical properties of PLA+

\begin{tabular}{|l|l|l|l|l|l|l|l|l|}
\hline Color & $\begin{array}{l}\text { Print } \\
\text { Temp. } \\
\left(\mathbf{c}^{\circ}\right)\end{array}$ & $\begin{array}{l}\text { Bed } \\
\text { Temp. } \\
\left(\mathbf{c}^{\circ}\right)\end{array}$ & $\begin{array}{l}\text { Density } \\
(\mathrm{g} / \mathrm{cm} 3)\end{array}$ & $\begin{array}{l}\text { Tensile } \\
\text { Strength } \\
(\mathrm{MPa})\end{array}$ & $\begin{array}{l}\text { Elongation at } \\
\text { break }(\%)\end{array}$ & $\begin{array}{l}\text { Flexural } \\
\text { Strength } \\
(\mathrm{MPa})\end{array}$ & $\begin{array}{l}\text { Flexural } \\
\text { Modulus (MPa) }\end{array}$ & $\begin{array}{l}\text { IZOD } \\
\text { Impact } \\
\text { Strength } \\
(\mathrm{KJ} / \mathrm{m} 2)\end{array}$ \\
\hline Blue & $\begin{array}{l}\mathbf{2 0 5}- \\
\mathbf{2 2 5}\end{array}$ & $\mathbf{6 0 - 8 0}$ & $\mathbf{1 . 2 5}$ & 65 & 12 & 75 & 2102 & 8.5 \\
\hline
\end{tabular}

Specimens preparation 
Printing of specimens

The design of the specimen is the first main actual step to begin in 3D printing. The geometry of the 3D printed tribological specimen was a cylindrical shape with a constant diameter of $10 \mathrm{~mm}$ and a constant height of $10 \mathrm{~mm}$. The second step is slicing the specimen and making its G-code according to selection values of printing parameters. Table 3 illustrates the fixed printing parameters used in the recent study. Finally, generated Gcodes were exported to ORIGINAL PRUSA i3 MK3 (FDM) 3D printer as shown in Fig. 1.

Table 3 The fixed printing parameters were used in this study during printing tribological specimens.

\begin{tabular}{|l|l|l|l|}
\hline printing parameter & Selected value & printing parameter & Selected value \\
\hline Layer height & $\mathbf{0 . 1} \mathrm{mm}$ & Print speed & $\mathbf{6 0} \mathrm{mm} / \mathrm{sec}$ \\
\hline Nozzle diameter & $\mathbf{0 . 4} \mathrm{mm}$ & Outer wall speed & $\mathbf{3 0 ~ m m} / \mathbf{s e c}$ \\
\hline Line width & $\mathbf{0 . 4} \mathrm{mm}$ & Enable print cooling & Yes \\
\hline Wall thickness & $\mathbf{0 . 4} \mathbf{~ m m}$ & $\begin{array}{l}\text { Build plate adhesion } \\
\text { type }\end{array}$ & Skirt \\
\hline Wall line count & $\mathbf{2}$ & Raster angle & $\mathbf{0}^{\circ}$ \\
\hline Top thickness & $\mathbf{0 ~ m m}$ & $\begin{array}{l}\text { Printing } \\
\text { temperatures }\end{array}$ & $\mathbf{2 1 5}^{\circ} \mathrm{C} / \mathbf{6 0}^{\circ} \mathrm{C}$ \\
\hline Bottom thickness & $\mathbf{0 . 4} \mathbf{~ m m}$ & Bottom line count & 1 \\
\hline
\end{tabular}

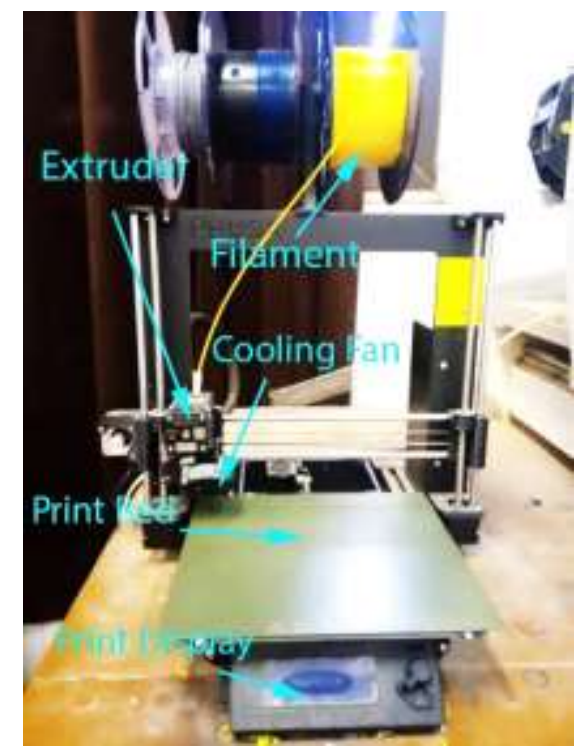

Fig. 1 The used 3D printer.

Tribological specimens preparation

It is necessary to fill anaerobic methacrylate into spaces of the printed parts without creating bubbles of air during the liquid impregnation. Therefore, each printed specimen except $100 \%$ of infill density parts had been placed in a pipe, which has an inner diameter of $10 \mathrm{~mm}$ and has a small hole in the bottom to leak the inner air during pressing operation. The anaerobic methacrylate had been put above the specimen in the pipe with enough amount and then a solid piston had been located above the anaerobic methacrylate in the pipe. Finally, the liquid had been pressed on a hydraulic press until the liquid began to leave the pipe from the small hole in the bottom maintaining a level of the liquid of $2 \mathbf{~ m m}$ 
above the upper surface of the sample to ensure the complete filling of the passages inside the tested sample. The specimens had been taken out of the pipe to dry for $\mathbf{4 8}$ hours.

Hardness of stainless-steel counterface

Vickers hardness (HV) test was used to measure the hardness value of counterface (CF) according to the ISO standards, [13] at room temperature. HV value of CF was $82 \mathrm{HV}$ 100. Table 5 shows the hardness test conditions and Fig. 2 presents the stainless steel counterface under microscopy after the hardness test was done.

Table 5 Vickers hardness test conditions

\begin{tabular}{|l|l|}
\hline Test parameters & Value of the parameter \\
\hline Shape of indentor & Diamond Pyramid shape with square base \\
\hline Acting force & 980 Newton \\
\hline Time of loading & 15 seconds \\
\hline
\end{tabular}

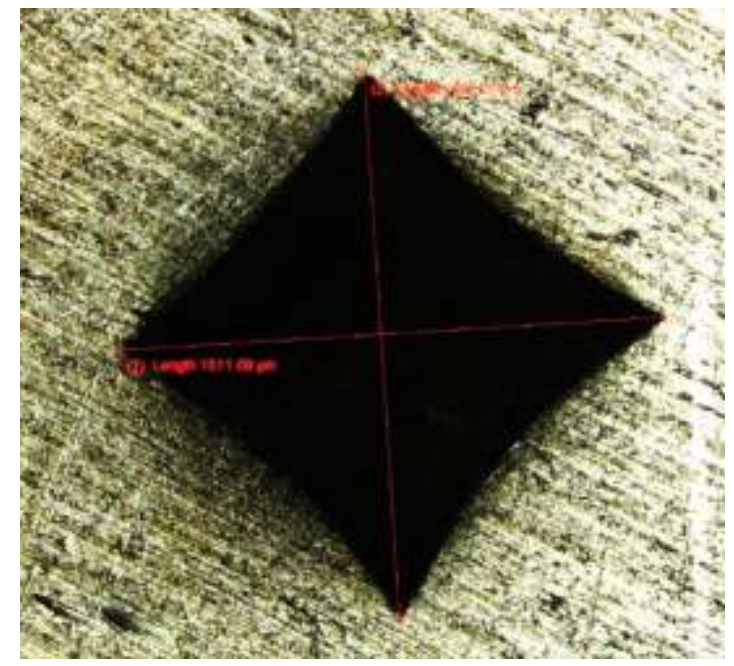

Fig. 2 The dimensions of the indentor on the counterface surface.

Tribology test

The frictional tests were the criterion tests to show the effect of impregnating the lubricant material into spaces of $3 \mathrm{D}$ printed specimens.

Tribometer

Pin on disc tribometer is used to evaluate the tribological properties of the Liquid lubricant impregnated PLA+ sample according to the ASTM standards [14]. Fig. 3 shows the used tribometer with details. The stainless-steel sheet $\mathrm{CF}$ is rotating with a speed of 500 RPM and all specimens were mounted at a distance of $30 \mathrm{~mm}$ away from the centerline of the counterface and subjected to a normal load of $8.65 \mathrm{~N}$ for 8 minutes. Before conducting the friction test, the counterfaces were cleaned with acetone to get rid of any contaminants and dirt. 


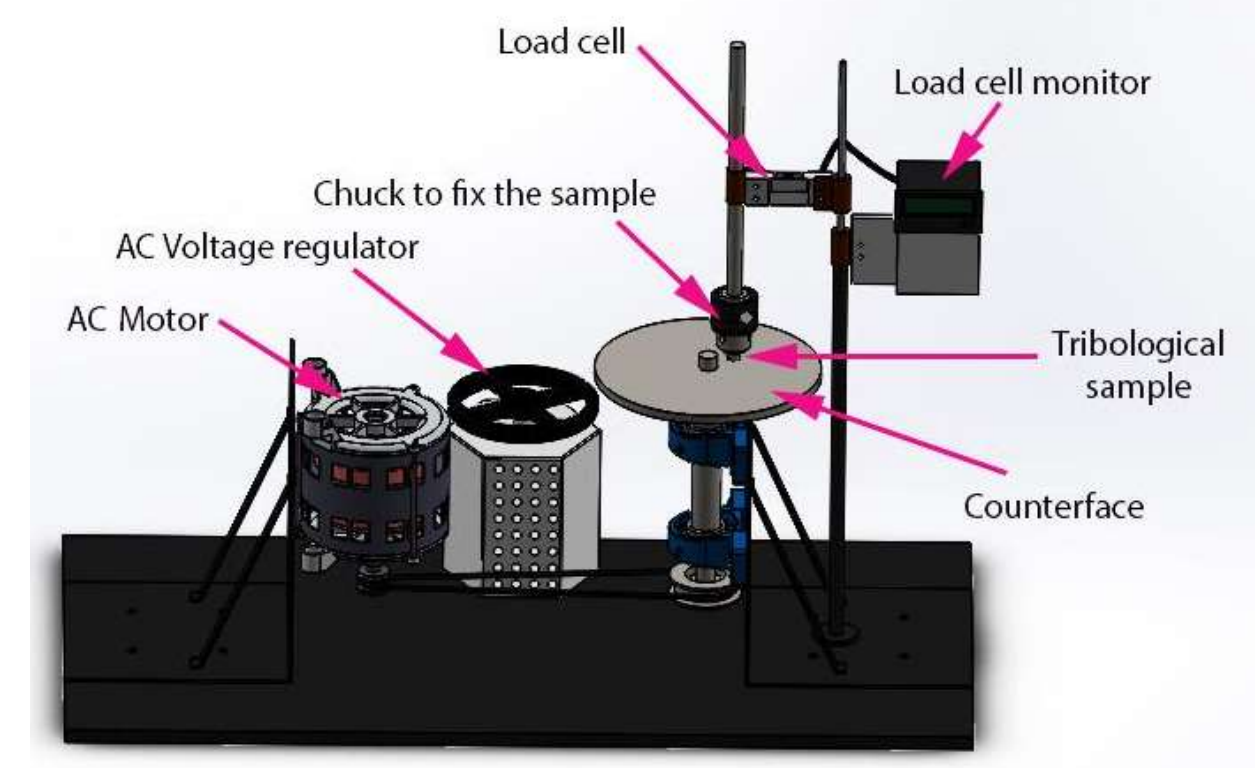

Fig. 3 The used pin on disc tribometer with details.

\section{RESULTS AND DISCUSSIONS}

\section{Friction Coefficients analysis}

Dry mode

It is clear friction coefficient $(\mu)$ is highly affected by infill patterns and infill densities. Certainly, the maximum amount of friction coefficient was in solid pattern $100 \%$ infill density which concentric, grid, and triangles pattern specimens had friction coefficients of almost $0.35,0.38$, and 0.26 , respectively. In the case of the dry mode test of $60 \%$ of infill density, it was found that the concentric pattern had the highest friction coefficient of almost 0.3. However, the lowest friction coefficient was recorded for the Triangles pattern (0.15). Meanwhile, in the case of $20 \%$ of infill density, it was noticed that the concentric pattern exhibited the highest coefficient of friction in the comparison with $60 \%$ of infill density. Nonetheless, the triangle pattern had the lowest coefficient of friction of nearly 0.18, as shown in Fig. 4.

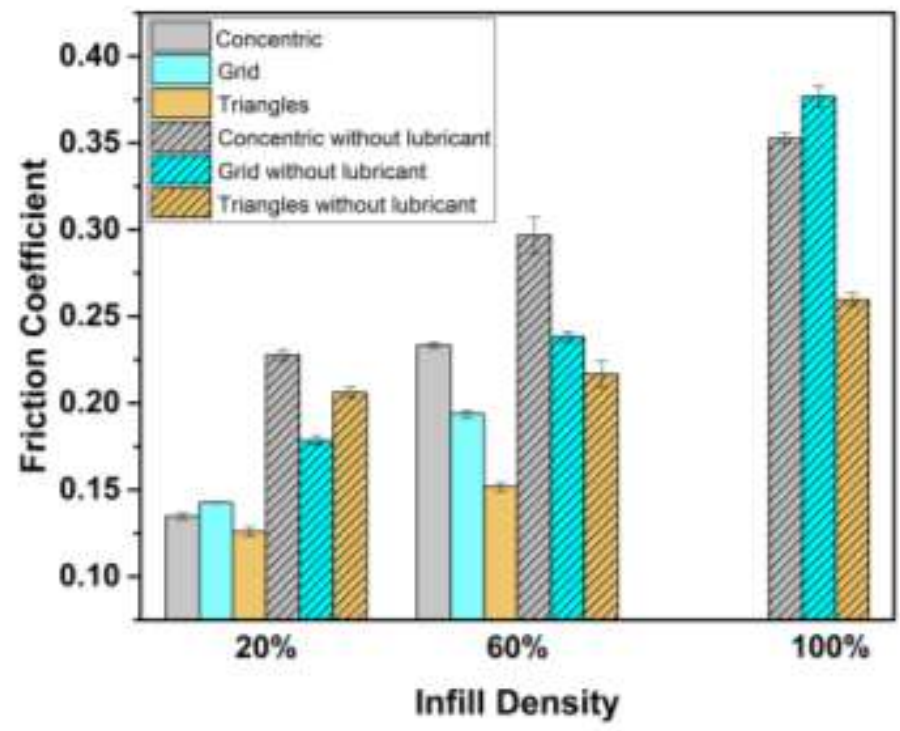

Fig. 4 The effects of infill pattern and infill density on friction coefficient. 


\section{Lubricant mode}

There is a significant effect due to loading the lubricants into the voids of $3 \mathrm{D}$ printed samples. Generally, the presence of the lubricant lessened the friction coefficient significantly at all cases of patterns and densities as shown in Fig. 4. Furthermore, in the case of comparison between lubricant and non-lubricant cases, the trend of friction coefficients of samples having different infill patterns with lubrication looks like the trend of the same samples without lubrication. The samples of $60 \%$ infill density recorded higher values of friction coefficients than the samples of $20 \%$ infill pattern. This may be referring to the higher amount of lubrication that exists in the samples of $20 \%$ infill density than the samples of $60 \%$ infill density. In the case of $60 \%$ infill density with lubricants, it was found that the concentric pattern had the highest coefficient of friction of about 0.23 . Meanwhile, the Triangles pattern had the lowest value of friction coefficient of about 0.15 . In the case of $20 \%$ infill density with lubrication, it was found that the Grid pattern had the highest value of friction coefficient of about 0.14 . On the other hand, the Triangles pattern had the lowest value of friction coefficient of about 0.12 , which may be referring to the volume of empty voids which was the highest in the Triangles pattern's sample ( meaning more lubrication) subsequently decreasing in friction coefficient, as shown in Fig.4. In the case of comparison between lubrication and non-lubrication cases, the trend of friction coefficients of samples having $20 \%$ infill density with lubrication doesn't look like the trend of the same samples without lubrication which may be occurring because of the large amount of liquid lubrication that exist in that samples and difficult to control in lubrication within the pin-on-disc test. It can be said that all samples with $20 \%$ infill density with lubrication have the lowest values of friction coefficients.

\section{Wear rates analysis}

Dry and Lubricant modes

Indeed, the infill pattern parameter has a noticeable effect on the wear rates of specimens, especially under the dry mode. Grid and Triangles pattern specimens had wear rates of almost 7.5 , and $8 \mathrm{~mm}^{3}$ respectively. That may be because of the rotational motion about the central axis of specimens during the experiment test, which means the dimensions of the frictional pattern were changing among maximum and minimum values of the dimensions during the test, thus there were different volumes of wear debris. Finally, wear debris was evaluated to give small values of wear rate. In the case of $60 \%$ infill density, an aerobic methacrylate lubrication plays a crucial role to minimize the wear rate. There are obvious wear rate differences between specimens without lubrication and specimens with lubrication. The concentric pattern specimen without lubrication and with lubrication had wear rates of almost 9.5 , and $3 \mathrm{~mm}^{3}$, respectively. The Grid pattern specimen without lubrication and with lubrication had wear rates of almost 14.5 , and $5 \mathrm{~mm}^{3}$, respectively. The Triangles pattern specimen without lubrication and with lubrication had wear rates of almost 7.5 , and $3.7 \mathrm{~mm}^{3}$, respectively. It should be noted the high effect of lubrication on the wear rates was noticed in the case of $20 \%$ infill density. The Concentric pattern specimen without lubrication and with lubrication had wear rates of almost 16 , and $6 \mathrm{~mm}^{3}$, respectively. The Grid pattern specimen without lubrication and with lubrication had wear rates of almost 17 , and $2 \mathrm{~mm}^{3}$, respectively. The Triangles pattern specimen without lubrication and with lubrication had wear rates of almost 9 and $2.5 \mathrm{~mm}^{3}$, respectively as shown in Fig. 4. The high differences in the wear rates in dry and lubrication modes in the cases of $20 \%$ and $60 \%$ infill densities referred to the amount of used lubrication in each case. The apparent differences of the wear rates in lubrication cases without regular rule of changing of the wear rate may be occurred because of going lubrication out and entering the wear debris instead of lubrication and sticking on the surface of the used 
specimen using the lubrication during friction test, which caused an increase in the wear rate. The remarkable decrease in the wear rate and friction coefficient of the PLA+ samples is attributed to the presence of the liquid anaerobic methacrylate lubricant in the contact region which leads to the indirect contact of rubbing surfaces in which a low-shear intermediate layer can be formed. This intermediate film allows the PLA+ samples to slide across the counterpart surface easily. Moreover, the apparent surface subjected to friction controls the wear rates of the tested samples. In the case of concentric samples, however, the surface subjected to the friction is small, in which the density of the void is the highest, it affects the strength of the walls of the lubrication passages whereas the higher density of the voids leads to weaker passages wall which can not stand against the shear resulting from the friction.

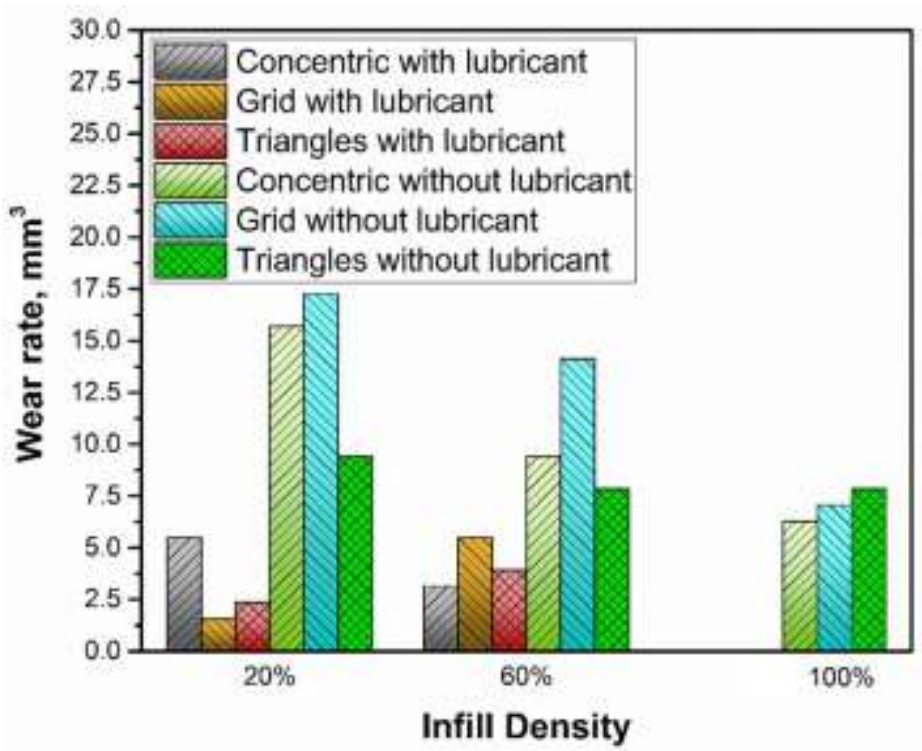

Fig. 5 The effects of infill pattern and infill density on the wear rate.

\section{CONCLUSIONS}

The recent study evaluates the tribological behavior of 3d printed PLA+ samples impregnated with the liquid anaerobic methacrylate lubricant with different infill densities and patterns. The main findings of the research can be shown below:

1. The liquid anaerobic methacrylate lubricant could decrease the friction coefficient significantly. This behavior is attributed to the indirect contact of the rubbing surfaces in which the anaerobic methacrylate forms a low shear intermediate film. This film facilitates the slipping of the PLA+ samples over the counterpart surface.

2. The wear rate of all infill densities and patterns decreases in the presence of the anaerobic methacrylate lubricant. This behavior is attributed to the formation of the protective film which prevents the severe damage and wear of the rubbing surfaces.

3. The infill densities play noticeable roles in the tribological behavior of $3 \mathrm{~d}$ printed PLA+. The lower friction coefficient is associated with the lower infill density (20\%). This could be attributed to the lower contact surfaces which are subjected to friction. Conversely, the higher friction coefficients are associated with higher infill densities.

4. In the absence of lubrication, lower infill densities recorded relatively higher wear rates. This behavior is referred to the large volume of the voids which weaken the samples against the high shear during the sliding. On the other hand, the samples were strengthened at a lower volume of voids. 


\section{REFERENCES}

[1] M. Picard, A.K. Mohanty, M. Misra, Recent advances in additive manufacturing of engineering thermoplastics: challenges and opportunities, RSC Advances, 10, pp. 36058 36089, (2020).

[2] Ü. Çevik, M. Kam, A review study on mechanical properties of obtained products by FDM method and metal/polymer composite filament production, Journal of Nanomaterials, 15, pp. 148 - 162 (2020).

[3] S. Singh, S. Ramakrishna, F. Berto, 3D Printing of polymer composites: A short review, Material Design \& Processing Communications, 2, pp. 97 - 108, (2020).

[4] J. Huang, Q. Chen, H. Jiang, B. Zou, L. Li, J. Liu, H. Yu, A survey of design methods for material extrusion polymer 3D printing, Virtual and Physical Prototyping, 15, pp. 148162, (2020).

[5] Q. Chen, J.D. Mangadlao, J. Wallat, A. De Leon, J.K. Pokorski, R.C. Advincula, 3D printing biocompatible polyurethane/poly (lactic acid)/graphene oxide nanocomposites: anisotropic properties, ACS applied materials \& interfaces, 9 (2017) pp. 4015 - 4023.

[6] K. Chizari, M.A. Daoud, A.R. Ravindran, D. Therriault, 3D printing of highly conductive nanocomposites for the functional optimization of liquid sensors, Small, 12, pp. 6076-6082, (2016).

[7] S. Kumar, R. Singh, T. Singh, A. Batish, Comparison of mechanical and morphological properties of 3-D printed functional prototypes: Multi and hybrid blended thermoplastic matrix, Journal of Thermoplastic Composite Materials, 0892705720925136, (2020)

[8] R.T.L. Ferreira, I.C. Amatte, T.A. Dutra, D. Bürger, Experimental characterization and micrography of 3D printed PLA and PLA reinforced with short carbon fibers, Composites Part B: Engineering, 124 (2017) 88-100.

[9] D.D. Singh, A.R. Reddy, S. Arjula, Characterization of Fused Deposition Modeling of PLA+ and Carbon Fiber-Pla components.

[10] E. Westphal, R. Mau, T. Dreier, H. Seitz, 3D printing of frames for anti-coronavirus face shields using different processes and materials, Transactions on Additive Manufacturing Meets Medicine, 2 (2020).

[11] H.S.A. Kumar, Effect of Various Infill Types on the Strength of the PLA+ Material in the Fused Deposition Modeling Process 15 (2020) 148-162.

[12] R.E. Przekop, M. Kujawa, W. Pawlak, M. Dobrosielska, B. Sztorch, W. Wieleba, Graphite modified polylactide (PLA) for 3D printed (FDM/FFF) sliding elements, Polymers, 12 (2020) 1250.

[13]DIN, 6507-1, "Metallic Materials-Vickers Hardness Test, International Organization for Standardization: Geneva, Switzerland, , pp. 4015 - 4023, (2005).

[14] ASTM G99-17, Standard Test Method for Wear Testing with a Pin-on-Disk Apparatus, ASTM International, West Conshohocken, PA, (2017). 